\title{
Intergenerational Auditor Program: Involving a Retired Professional in the Classroom
}

\author{
Alan Lai*, Solna Lin Na Xing, and Ghee W. Ho \\ BNU-HKBU United International College
}

\begin{abstract}
Most literature regarding involvement of retired adults in the classroom focuses on feasibility rather than benefits directly perceived by individuals, let alone the lack of research on academic learning purposes. This report presents the pilot action of an intergenerational (IG) approach/program, within which a retired professional crossed the border (i.e., from Hong Kong to China Mainland) and engaged a class of ESL (English as a second language) undergraduate learners - as an auditor - in a credit-bearing course. The program was staged through intergenerational programming in terms of purposeful planning and activity design to facilitate contacts between young and old. Post-program responses to Likertbased scales and open-ended questions were employed to examine what perceived benefits across generations could be found after program implementation, thereby examining the value of intergenerational learning through the pilot action. Evaluation findings indicated that the value of intergenerational learning can be conceptualized as a pathway leading to benefits perceivable across generations and the significance of academic learning purposes valued by young and old. Despite benefits found, the auditor approach is arguably a way of working due to lessons learned. Further studies should investigate how an auditor system like the program could contribute to the goal of promoting impactful results in other course settings. Explicit appreciation of the retired citizen's involved is also documented as a concluding note.
\end{abstract}

Keywords: intergenerational program, auditor, ESL, health psychology, perceived benefits

*Corresponding author: Alan Lai. Email: alanlai@uic.edu.cn 


\section{Introduction}

Most published details regarding the teaching and learning practice of involving retired citizens or the aged in a classroom and having them engage students mainly focus on feasibility (Dauenhauer et al., 2018; Doll, 2006; Heffer-nan et al., 2019; Krout \& Pogorzala, 2002). It is little known as to how this kind of practice may lead to evidence-based benefits to individuals - it is even more unknown as the shared site is placed in a credit-bearing course - relevant evidence and caveats are scarcely documented.

The practice is of evidence though. For example, an auditor approach has been brought to the high school system in Japan since 2002 (Nishita \& Nakagawa, 2015). Its first launch began at Fuso Junior High School in Fuso Town of Aichi Prefecture (K. Mizobe, personal communication, December 19, 2015). The program involves a senior retired citizen in a history class as an auditor, a voluntary role that empowers the retired citizen to interact with high schoolers, share stories, and learn together. In reporting the evaluation of the auditor approach, Mizobe (2017) emphasized that it has made possible on yielding positive outcomes, such as younger and older participants' positive comments and compliments to the system; however, direct benefits to individuals are yet revealed. In addition, whether retired citizens with a professional background could also benefit from the auditor approach remains unknown.

Likewise, the City University of Hong Kong is another one currently adopting a similar approach - it aims to match retired adults with undergraduate students in a wide range of credit-bearing courses (The Elder Academy of Hong Kong, 2019). It has demonstrated significant capability to foster lifelong education, and especially in the case of weaving retired adults into an undergraduate structure through friendship-building. For example, an older participant's reflection revealed such a way of working: "After 4.5 years of study, many classmates and I become good friends and we were in communication with each other" (City University of Hong KongScope, 2019, p. 17). To learn more about benefits for both retired adults and undergraduate students - especially in the context of academic learning purposes, further research is suggested.

\section{Intergenerational-ESL Auditor Program}

Inspired by the examples with demonstrated outcomes, a pilot project titled The Intergenerational-ESL Auditor Program (IG-ESL AP) was launched. Most broad- 
ly, it aims to enrich undergraduate education while offering students opportunities to practice English as a second language (ESL). IG-ESL AP was rolled out at a private college (located in Zhuhai, Chinese mainland) - it adopts the policy of using English language as the medium of instruction, a pioneering feature of higher education in the nation. Additionally, the college follows an authentic learning "directive" - i.e., accepting the challenge of providing learners with opportunities and authentic materials to learn meaningfully (BNU-HKBU United International College, 2018, p. 200).

In the project, IG-ESL AP was applied in an undergraduate course of psychology. Health psychology was chosen due to the first author's teaching practice - that is, maintaining the exercise of teaching duties assigned and fulfilling the need of delivering the course with authentic materials to help students understand course contents meaningfully - it is thus a practice shaped by the challenge as well.

According to the syllabus, the course aims to view health and illness through a biopsychosocial lens - it is a framework arguing that well-being is a result of complex biological, social, and psychological factors. With this in mind, students are expected to relate knowledge to health-promoting behaviors for personal growth.
Students are also offered opportunities to learn from supporting materials based on Traditional Chinese Medicine (TCM) for course/lecture topics about modifying health-related behaviors; coping with stress or pain; and dealing with illnesses.

All in all, the objectives of IG-ESL AP, when applied during the course of Health Psychology, were to (1) increase opportunities for college students to practice English language, and (2) contribute to students' learning experience.

\section{Research Questions}

In light of the scarcity of evidence with respect to benefits of getting the intergenerational auditor approach applied in an undergraduate setting, we asked two questions. First, what would be the benefits, if any, perceived by undergraduate students in the course of health psychology? Second, in what ways would the program be perceived beneficial to the retired professional after completing the IG-ESL AP process? Both inquiries are in general raised with regard to the scarcity of understanding in the literature. Results derived from them could also contribute to informing the practice of college teaching, such as gaining a better understanding of the approach as a way of working or not on providing opportunities for academic 
learning in a meaningful way. Additionally, the second one is also considered as a way to judge whether IG-ESL AP could match the retired professional expectations towards the approach. Learning more from it is significant to program promotion and dissemination in the future.

\section{Methodology: Intergenerational Programming}

\section{Participants}

The senior (age $=60$ ) who participated in this program was a retired professional from Hong Kong. Before retirement, he worked in a private hospital in Hong Kong as a security specialist of information technology. He also had a master's degree in health informatics. He was selected due to his high-level proficiency in English language, his health-related expertise as well as his prior voluntary experience in another IG program organized by the first author.

Student participants $(n=40)$ were from health psychology, a credit-bearing undergraduate course provided by the department of applied psychology. Many of these students were in their early twenties (mean age $=22.26$ ), taking the course in a semester prior to graduation. They were native Mandarin and ESL speakers. They took the course for 12 weeks, and each weekly lesson lasted for three hours. The average attendance rate of the entire course was $95 \%$. The placement of one auditor in the class is the least ratio considered feasible in prior programs like the current study (Mizobe, 2017). Since health psychology was a required course, exposure to the involvement of a retired professional as an auditor in the lecture room was equal among the entire cohort of final year students. They were given this exposure notice in the first lesson. In considering the exposure an opportunity for purposeful communication with a (retired) professional, all students agreed to accept this auditor approach.

To ensure acceptance further, all participants provided written consent for joining the program, being aware that participation was voluntary and data would be anonymized for publication purposes. The project met the college's ethical assessment guidelines, meaning that an ethical approval was obtained prior to research.

\section{Pre-program and Implementation Arrangements}

Before the program began, the retired professional was given a pre-program interview. The purpose was to understand what expectations he might have prior to 
his on-site participation. The interview was unstructured, and it was expected to help design post-program questions for reflections. During the interview, the project team learned that he had been exploring ways since his retirement two years ago - to stay active, feel healthier and enhanced for personal development, and find a meaningful academic learning opportunity. These expectations served as a framework for designing the post-program reflection survey.

During the implementation period, he crossed the border and traveled to Zhuhai from Hong Kong via Hong Kong-Zhuhai-Macau Bridge (HZMB). This new passageway opened in 2018 (i.e., nearly nine months before IG-ESL AP began), dramatically shortening the passage time of traveling among the adjacent cities from around three hours to within 60 minutes. To participate in the program, the retired professionalwas offered travel insurance, meals, and stipends. Travel expenses were also covered. A budget totaling RMB6000 (or USD840) had been approved by the college before the program began. Upon completion, he was awarded a certificate of appreciation.

\section{Program Design}

The program was implemented within course hours throughout a 12-week semes- ter. In each week, a two-hour lecture was immediately followed by a one-hour activity time.

Except the first and the last two weeks, the retired professional and college students met each other for three hours weekly - they thus met nine times in total. They attended lectures together; shared coursework topics; and engaged each other through IG activities in class. During each lecture, he chose himself the frontmost row, being seated like other students. Unlike a teaching assistant or a tutor with official duties, he showed up every time as an auditor - that is, a co-learner with his presence or a focus of tendency offering opportunities for students to practice English; sharing life experiences; and learning with students alongside for coursework activities, projects, tasks, and discussions as a partner.

\section{Intergenerational Activities}

The literature indicates that contacts between people of different generations are most meaningful when IG activities are carefully programmed (Galbraith, et al., 2015; Henkin \& Sweeney, 1989; So \& Shek, 2011). In the intergenerational field especially focused on teaching and learning, activities designed according to objectives or lecture-related contents have been 
found conducive to partnerships and sharing between skipped generations as well as personal growth in higher education settings (Kaplan et al., 2017; Lai \& Kaplan, 2016). Before the program began, ten IG activities were planned by the course instructor according to course/lecture topics:

- Activity 1: The retired professional and students discussed how traditional Chinese medicine (TCM) may fit better with the (1) biomedical or (2) biopsychosocial model. These two models were the main key themes of the lecture topic about "What is Health Psychology?"

- Activity 2: The retired professionalshared with students his eating habits, hobbies, and living style. The lecture topic about health promoting behaviors contributing to eating habits inspired the design of this activity.

- Activity 3: The retired professionaland students provided as many examples as possible, pinpointing how TCM describes the body systems differently from western perspective. This activity is associated with the lecture topic about "The Systems of the Body."

- Activity 4: The retired professionaland students learned from their personal experiences, health psychology, and TCM regarding insomnia. In the lec- ture, emphasis was greatly given to contents about health-promoting behavior and sleep disorders.

- Activity 5: With comments provided by the volunteer, students designed bookmarks to encourage smokers to quit smoking. A main focus of the lecture was about health-compromising behaviors leading to smoking.

- Activity 6: The retired professional shared with students about his stressful experiences. Since the lecture topic was about "Stress," this sharing activity was believed to be relevant and meaningful.

- Activity 7: The retired professional s and students co-design posters about stress management. This activity was associated with the lecture about coping of stress and resilience.

- Activity 8: The retired professional slearned from students about ways to manage pain currently experienced by him or friends of his age. To relate learning to the lecture about pain management, this activity was designed.

- Activity 9: The retired professional sshared with a group of students about his or his relatives' experiences with TCM and western medicine. The lecture of the week was about "Using Health Services," and this activity served as a way to relate lecture con- 
tents to real-life experiences.

- Activity 10: The retired professional sand students learned together how to handle stroke from TCM and western approaches. Stroke was one of the major health-related issues corresponding to the lecture about "Managing Chronic Illness".

Of note, all lectures and activities were conducted every Monday evening. The retired professional did not participate in the last two weeks due to course exams.

\section{Engagement Strategies}

Intergenerational activities were programmed in ways that the whole class of students would have shared opportunities to interact with the retired professional. Most broadly, programming of the activities is based on a series of engagement strategies through an IG model aimed to transform a classroom setting into an intergenererational contact zone (ICZ). According to the latest ICZ model (Kaplan et al., 2020), intergenerational learning is a developmental approach - conceptually, it refers to characteristics of dimensions/ ways or engagement strategies to design and serve for older and younger generations to engage each other, facilitate friendly partnerships, and co-construct for meaning-making such as addressing issues or accomplishing object-oriented tasks. As approached by IG-ESL AP, an ICZ based in the course under concern was precisely done so through the engagement strategies of (1) group dynamics, (2) decision-making, (3) choice, (4) coalition, (5) guest speech, (6) role play, and (7) interview. Further descriptions of each strategy and their relations to activities are provided in the list below:

(1) Group dynamics: It is a sociocultural dimension of ICZ model "to use the [teaching and learning] environment to pursue desired social contact, relationships, and affiliation within and between generations" (Kaplan et al., 2020 , p. 5). In activities 1, 2, 3, 5 and 9 , all students broke into ten groups. The retired professional joined them one by one, thereby offering comments, providing support, sharing stories or collecting information from students.

(2) Decision-making: It is a political dimension "to determine who is 'incharge'? - social and institutional power structures for making decisions about how a space is developed ... over time" (p. 5). In activities 5 \& 7 , the retired professional determined which student groups were winners. 
In activity 9 , the retired professional determined which group to join.

(3) Choice: It is an ethical dimension "to provide people with choice with regard to how they utilize ICZ spaces and engage others." For example, in the classroom, all learners may prefer their learning to be "active" like sitting in the front-most row in class. In activities 4 and 10, the retired professional chose a particular group to join for completing a task.

(4) Coalition (for class inquiries): It is the second political dimension to create specific "pathways for participation" (p. 5). In activities 3 and 5, a group was first determined by the retired professional to be the best in completing a task. Next, they formed a coalition for addressing class inquiries.

(5) Guest speech: It is a psychological/ perceptual dimension which allows for "encompas[sing] multiple layers of shared meaning and experience" (p. 5). In activity 2,8 and 9, the retired professional shared real-life experiences and professional knowledge before class.

(6) Role-play: It is a second sociocultural dimension with an emphasis on using the classroom environment "to practice and maintain activities con- sistent with cultural traditions and local heritage" (p. 5). In activity 9 , the retired professional and a small group of students presented their discussion results through role-play (i.e., a seven-minute drama). More specifically, the role-play was about informing family members of a patient's dying symptoms, and doing so, they were asked to play the roles of a TCM partitioner, a Western medical practitioner, and family members of a patient with dying symptoms.

(7) Interview: It is a physical/flexible dimension with which the teaching or learning environment can "accommodate changes over time in user needs, abilities, interests, concerns etc." (p. 5). In activity 3, the older adults were interviewed by a few groups of students only when they would consider necessary (i.e., on demand). But in activity 6 , he was interviewed by the whole class of students.

To illustrate how activities worked with engagement strategies, here is an example. For the course topic about "Syptoms of Dying Patients," two hours were first spent during the lecture time focusing on literature and theories. Immediately followed by a one-hour activity-based lesson, strategies 
1, 2, 5 and 6 were employed. As a result, (1) the whole class was first broken into ten different groups; (2) the retired professional determining which group of students to join; (3) the older adult and students engaging each other for the role-play; and then (4) the retired professional delivering a speech before class with regard to his life experiences about families or friends with dying symptoms.

\section{Post-program Arrangements}

To respond to the research questions, all participants reflected on the program within two weeks after the last class. A post-program evaluation survey with nine lead-in questions was used to help them document their program experiences, perceived benefits, and recommendations. Each question included two parts. First, respondents were introduced to Likert scalebased questions, which are a set of symmetrical five-point rating scales including the items of -2 or strongly disagree; -1 or disagree; 0 or not sure; 1 or agree; and 2 or strongly agree. In the second part using open-ended questions, respondents were asked to provide explanations, examples, or thinking to support their scaling responses. As a result, all students and the retired professional $(\mathrm{n}=41)$ completed all of them.
The use of Likert scales supplimented by opened questions needs to be explained further. First, there is a body of research using Likert scales and expanded questions in the program profile study for evaluating benefits perceived by participants of different generations like the current study (e.g., Lai \& He, 2020; Lai \& Xing, 2021). As to the focus of perceived benefits, it have been found significant in developmental and aging studies to indicate a positive way of life driven by thinking, intentionality or attitudes across ages. One of the earliest seminal examples is Becker's (1974) Health Belief Model using perceived benefits to predict health-promoting behaviors in the field of behavioral medicine.

For data analysis, Likert-based scales are simple sums or averages of questionnaire responses over each individual item (question). Documented responses of open-ended questions were categorized into themes, with the purpose of relating distinctive nature of benefits perceived by participants to relevant program objectives and contexts. Two project team members also discussed this type of qualitative work, so that its value would be able to lie within the possibility of understanding quantitative evidence like the Likert-based scales of this study in a meaningful way while presenting the loss of relevant details (Silverman, 2006). 


\section{Results}

In general, $90 \%$ of the student members either agreed or strongly agreed (i.e., mean score of rating $=1.10$ ) that they perceived benefits from the program. Both quantitative and qualitative data indicated that benefits were reported with the themes of (1) opportunities to practice English in class; (2) academic learning; (3) course curriculum; (4) personal development; and (5) surendipitous experience:

\section{Gaining opportunities to practice} English: 36 out of 40 students (i.e., $90 \%$ ) either agreed or strongly agreed (i.e., mean score of rating $=1.26$ ) that they received more opportunities to practice English as a second language in class through the program. When asked to provide an example, one student said, “... Peter (a pseudonym) joined our group discussion part and we had to interact with him in English." Another student provided a more thorough example, saying "Sure, we can use English to communicate with the old man. While he shared his experience with us, we asked many questions by using English, also, many terminologies were used to express some contents connected with health psychology. So in a word, I think it is a good way to develop my
English skills." Besides group discussion, one student found interview as a fruitful strategy of engagement, saying "In a lesson about the stress of retired citizens, all groups in our class interviewed Peter about his experience and opinion. That was an active conversation because Peter was quite helpful and answer all of our questions. Through this kind of talking, our English ability of conversation could be improved."

2. Feeling more active in academic learning: When asked whether the students experienced academically more active through the auditor program, they also responded to this item positively. First, the mean score of ratings at 0.95 means that 9 out of the 40 students were not sure while one student disagreed, but 27 students or $73 \%$ of the class either agreed or strongly agreed that they felt academically more active. From the qualitative data set, it is not difficult to find example quotes alluding to the positive rating. For instance, one student said, "Peter is an admired and positive man that with his participation made class more active." Another student provided an explanation in terms of the auditor nature of the program, saying "Peter came as a 'classmate', a 'friend', I 
think most of us still shared a common sense that 'Here comes a successful idol' and wanted to try our best to inspire him, or just try not to make any mistakes. So I would say that with the older generation partner, students would be more active."

\section{Feeling more meaningful in learning} health psychology: In addition to the more active experience, a majority of the students reported that they found the health psychology curriculum more meaningful. Except three students who either disagreed and felt unsure, 34 students or $92 \%$ of them (i.e., mean score of rating $=1.21$ ) agreed or strongly agreed in this regard. When asked why they would feel benefited in this way, one student provided an internalized explanation in an IG context: "Connect the younger and older learner with each other to exchange their idea about health can bring out more creative and constructive conclusion. No matter younger or older citizen, the agreement concluded by both sides is better than single one definitely." Another student said it was due to the life experience sharing between them and the volunteer: "I think [the program] is good for us to better understand the theory of health psychology because [the] elder can share many examples for us."

\section{Gaining insights for personal devel-} opment: The students also seemed to have gained a range of insights into their personal development through the program. First, except four students who were not sure about this aspect of experience, 33 students or $89 \%$ of them either agreed or strongly agreed to the item (i.e., mean score of rating $=1.01)$. Many of them explained the positive insights arose from the volunteer's participation. For example, one student said, "I think what I've learnt from Peter is the strong self-discipline, he exercised a lot and participated in lots of events. He also borrowed the textbook and listened to every lecture carefully. To me, it indicated that I also have the opportunity to keep studying at any period of my lifetime." Likewise, another student said, “... I was surprised by Peter's healthy lifestyle. Now, I start to pay more attention about the components of what I eat like the snacks and what I drink. And I am trying to get up and go to bed early." Perhaps, even lifelong insights might have been generated through the program. For example, this student said, "I really admire the retired life of the old man, it gave me a space to think about my retired life, 
80 Alan Lai et al.

what I want to do, and what I really like to do." Insights about health were also seen. One of the students said, "I become more focus on personal health learned from the retired citizen's healthy habits."

5. Encountering serendipitous experience: Unexpected results/benefits were also found. Seven students did not expect that they would perceive elders in a more positive or even a "younger" way. For example, one student said, "... [Peter] is quite different from my expectation as he is very healthy and has a young mind." Another student undoubtedly experienced a stark difference of change: "Before communicating with [Peter], I think the elder should be someone with weak body and be a bit of wordy. After courses, I changed the stereotype for the elders."

As to benefits reported by the retired professional, he strongly agreed (i.e., score =2) that he felt (1) staying active, (2) healthier, (3) enhanced in personal development, and (4) meaningful in academic learning through the program. Below are the four outcomes along with example quotes:

1. Staying active: "The activities and particularly the part of interacting with the students made me feel staying active."

2. Feeling healthier: "First of all, the textbook and the lecture about health psychology made feel healthier. But when the students asked questions, it gave me a chance to review my health, and that really made me feel psychologically, physically and mentally healthier."

3. Feeling enhanced in personal development: "In the program, I strongly feel that I would like to contribute myself not just in Hong Kong but cross the border and help more generations of people. I think the program has changed the way how I pursue my voluntary work in the IG area."

\section{Feeling meaningful in academic} learning: "The program did offer me a lot of opportunities to learn in an academic way. It is very meaningful to me since I could learn a lot of things new and useful for my well-being."

These post-program results appeared to serve the retired professional's pre-program expectations.

\section{Discussion}

Teaching and learning have typically 
been characterized by contacts between younger and older, less experienced and more, or novice and expert. Yet, to understand how the contacts play out especially the involvement of people with a retired identity in an undergraduate credit-bearing setting, it is important to attend to inclusion of different generations like the current study, which allowed for contacts between a retired professional and a group of young students in the course of health psychology. The notion of skipped-generational relationships is then embedded in the shared setting, a co-shared contact zone through which intergenerational learning is conceptualized as a potential pathway leading to benefits perceivable to people across ages. In this case, through the use of research inquires, intergenerational programming, program implementation of IG-ESL AP, evaluation tools for collecting quantitiatve and qualitative evidence, and analysis, intergeneraitonal learning in a credit-bearing college environment was found in different ways perceivably beneficial to people of different generations. To the young students, benefits were perceived in terms of English language practice; academic learning; health psychology curriculum; personal development; and serendipitous experience. Likewise, the retired professional found the program beneficial in the areas of staying active, feeling healthier, personal development, and academic learning. In considering the particular evidence regarding academic learning offered by the young students and the retired professional, it seems IGESL AP is a way of working, especially through which opportunities for learning more meaningfully were provided, thereby matching the course with the college directive/policy more closely. This approach is thus an additional support to the evaluation findings of the Elder Academy's auditor program (City University of Hong KongScope, 2019). Besides, their emphasis is in many ways highlighting intergeneraitonal friendship as a way of working for connecting skipped generations through the auditor approach while the current study focused on how intergenerational learning contributed to the academic learning of young and old together - both young and old of the current study considered academic learning to become more active and meaningful as the common and co-shared benefit. Intergenerational learning can thus be considered as a pathway, as demonstrated in this case, leading to benefits with academic learning purposes equally salient and significant to people across ages and the program per se.

These two sets of positive results, when seen together, are also in line with Mizobe's (2017) auditor program evalua- 
tions, demonstrating further that a person who is retired and with a professional background could also benefit from the auditor approach.

In spite of benefits seen, the program also received criticism from participants - IGESL AP is thus arguably yet a way of working in this sense. Three lessons learned and proposed actions for improvement are summarized as below:

(1) Demand of auditors: Students ( $\mathrm{n}=$ 13) commented that more than one retired professional should have been recruited because "the discussing time left for every group is not enough." In this regard, more than one retired citizen to engage the same group of students may help make a difference.

(2) Possibility of getting children involved: There are recommendations $(n=3)$ suggesting that children be invited to join. For example, one student said that children could get involved in the program design and winner judgement levels. In doing so, the project team will consider the possibility of inviting children, and probably their parents may also contribute to the program.

(3) Age-friendly arrangement: There is a suggestion from the retired profes- sional $(\mathrm{n}=1)$ that the program need be restructured in an age-friendlier way. For example, the campus needs to be brighter during the evening time - for both young and old. Also, wet floors were seen at times due to rain and cleaning. For safety purposes, there may be a need for hiking sticks, flashlights, student guides, a daytime schedule, better floor management, etc.

\section{Conclusion}

In this project, contacts between young and old for teaching and learning purposes have led to results that seem to be impactful. However, they are based on findings only drawn from a single case or an undergraduate course. A closer look into the outcomes of this project (e.g., increased opportunities for English language practice, enhanced understanding on course contents, increased exchanges of lived experiences, etc.) can be achieved through replications.

With the lens of longer hindsight, the project team might want to have a further look into the component of cross-border engagements - a student participant's quote seems to support this idea, saying "This program helps strengthen cross-border contacts between skipped genera- 
tions..." Additionally, if it is looked at with themes such as lifelong learning, living, and language (see Kaplan, Thang, Sanchez, \& Hoffman, 2016), it might also begin to bear more central, spillover, and/ or surendipitious outcomes.

As a final remark, the retired professional's efforts are recognized and appreciated. The following quote from a student further supports this concluding note:

"I really appreciate what Peter had done for us and that is very meaningful for us youth. He helped us learn more knowledge and skills from circumstances in real life."

\section{Acknowledgements}

We would like to express our gratitude to Ms. Lesley He for all the operational and research supports. We are also grateful to both reviewers for their comments. This research is supported by the first author's BNU-HKBU UIC Research Grant and the third author's 2018 Guangdong University Innovation and Enhancement Programme (R5201814).

\section{References}

Becker, M. H. (Ed.). (1974). The health belief model and personal health behavior. Health Education Monographs, 2, 324-473.

BNU-HKBU United International College. (2018). Undergraduate handbook 20182019 (for 2018 admission). Retrieved May 4, 2021, from https://ar.uic.edu.cn/ info/1029/1033.htm

City University of Hong Kong-Scope. (2019). CityU elder academic $10^{\text {th }}$ anniversary. Hong Kong: Design and Production Services UP CityU. Retrieved May 4, 2021, from https://issuu.com/cityuscope/docs/elderacademy

Dauenhauer, J. A., Heffernan, K. M., \& Cesnales, N. I. (2018). Promoting intergenerational learning in higher education: Older adult perspectives on course auditing. Educational Gerontology, 44(11), 732-740. https://doi.org/10.1080/03601277.2018.1555358

Doll, G. A. (2006). Enhancing gerontology education: The role of older adult auditors in a human development and aging course. Journal of Intergenerational Relationships, 4(3), 63-72. https://doi.org/10.1300/J194v04n03_05

City University of Hong Kong. (2019). Elder academy at City University of Hong Kong. 
84 Alan Lai et al.

Retrieved September 27, 2019 from https://www.scope.edu/Home/Programmes/DiplomaCertificateandShortCourse/ElderAcademyatCityUniversityofHongKong.aspx

Galbraith, B., Larkin, H., Moorhouse, A., \& Oomen, T. (2015). Intergenerational programs for persons with dementia: A scoping review. Journal of Gerontological Social Work, 58(4), 357-378. https://doi.org/10.1080/01634372.2015.1008166

Henkin, N. Z., \& Sweeney, S. W. (1989). Linking systems: A systems approach to IG programming. Journal of Children in Contemporary Society, 20(3-4), 165-172. https:// doi.org/10.1300/J274v20n03_16

Heffernan, K., Cesnales, N., \& Dauenhauer, J. (2019). Creating intergenerational learningopportunities in multigenerational college classrooms: Faculty perceptions and expe-riences. Gerontology \& Geriatrics Education, 40(2),1-14. https://doi.org/10.1080/ 02701960.2019 .1613235

Kaplan, M., Sanchez, M., \& Hoffman, J. (2017). Intergenerational pathways to a sustainable society. Springer International Publishing. https://link.springer.com/ book/10.1007/978-3-319-47019-1

Kaplan, M., Thang, L. L., Sanchez, M. \& Hoffman, J. (Eds.). (2016). Intergenerational contact zones : A compendium of applications. Penn State Ex-tension

Kaplan, M., Thang, L. L., Sanchez, M. \& Hoffman, J. (Eds.).(2020). Intergenerational contact zones : Place-based strategies for promoting social inclusion and belonging. Routledge. https://bit.ly/3cDIopO

Krout, J. A., \& Pogorzala, C. H. (2002). An intergenerational partnership between a college and congregate housing facility: How it works, what it means. The Gerontologist, 42(6), 853-858. https://doi.org/10.1093/geront/42.6.853

Lai, A., \& Kaplan, M. (2016). Weaving intergenerational engagement into ESL instruction: Case study of a university-based program in Hong Kong. International Journal of Teaching and Learning in Higher Education, 28(2), 254-264. https://doi.org/10.1080/ 15350770.2013 .839285

Lai, A., \& He, J. L. (2020). A cross-cultural, intergenerational activity:"Experience, learn and have fun... learning journey" program profile. Journal of Intergenerational Relationships, 18(2), 253-260. https://doi.org/10.1080/15350770.2020.1747586 
Lai, A., \& Xing, S. L. N. (2021). Intergenerational health review: Learning about older adults' reminiscence through a college course project. Journal of Intergenerational Relationships, 1-9. https://doi.org/10.1080/15350770.2021.1897727

Mizobe, K. (2017). Re-learning system for the elderly in the elementary/junior high school. In A. Kusano, K. Mizobe, H. Uchida, \& M. Yasunaga (Eds.), The theory and practices of intergenerational learning; Series 2: Future of the intergenerational exchange as the world standard (pp. 244-245). Sangaku Publishing Co., Ltd.

Nishita, C. M., \& Nakagawa, A. S. (2015, July 21-24). Intergenerational action on a global scale conference: A recap [Conference session]. Generations United, Honolulu, Hawaii, United States.

Silverman, D. (Ed.). (2016). Qualitative Research. Sage.

So, K. M., \& Shek, D. T. (2011). Elder lifelong learning, IG solidarity and positive youth development: The case of Hong Kong. International Journal of Adolescent Medicine and Health, 23(2), 85-92. https://doi.org/10.1515/ijamh.2011.016

The Elder Academy of Hong Kong. (2019). Retrieved September 27, 2019 from https:// www.scope.edu/Home/Programmes/DiplomaCertificateandShortCourse/ElderAcademyatCityUniversityofHongKong.aspx. 